\title{
L2 WRITING STRATEGIES USED BY HIGH SCHOOL STUDENTS
}

\author{
Syaadiah Arifin 1 \\ ${ }^{1}$ Universitas Muhammadiyah Prof. Dr. Hamka Jakarta \\ ${ }^{1}$ syaadiah.arifin@uhamka.ac.id
}

\begin{abstract}
Writing is a challenging activity that comprises a complex cognitive process, as well as various strategies. Furthermore, minimal research has been performed on using writing strategies among High School students in the EFL context, specifically in Indonesia. Although the applications of effective strategies have been evidenced to be helpful, many students are not aware of using them to alleviate their writing quality. Therefore, this study aims at investigating English L2 strategies when writing recount texts using three skilled English students. This is a qualitative research that utilized purposive sampling and the instruments employed were Think-Aloud Protocols (TAPs), observation, retrospective, and semi-structured interviews. Following the analysis and interpretation of the data obtained from these instruments, the acquired results demonstrated that they used similar writing strategies. However, the occurrences from this use differed from one individual to another as some were unaware that the writing process was recursive and not linear. Therefore, this study implies that students need to be encouraged to apply different strategies to develop their writing, and teachers also, were required to explicitly teach these strategies as it will lead students to use them effectively. Training on the use of writing strategies is needed for Indonesian students to support and help them write efficiently in English.
\end{abstract}

Keywords: Writing Strategies, Skilled High School Students, Think-Aloud Protocols (TAPs)

\section{INTRODUCTION}

Language teachers are usually confronted with various errors produced by students while tutoring, and a significant problem encountered is writing because it is a difficult skill to learn and practice (Pablo \& Lasaten, 2018). For some students, writing in either their native or learned language causes a great challenge and the most difficult part is having to generate coherent, accurate, and lengthy texts (Nunan, 1999). Another problem frequently encountered is with grammar skills, which are quite tedious for EFL students (Farooq \& Uzair-ul-hassan, 2012). This is obvious when discussing writing proficiency, and is likely related to the mastery of English grammar or structure. Students have to deal with accurate sentence structures, paragraph development, and tenses, coherent text production, parallel construction, as well as subject-verb agreement (Mbau \& Marhum, 2014).

Writing is a rudimentary skill that should be mastered by Senior High school students (SMA/ SMK) according to the 2013 curriculum Kurtilas in Indonesia. They are required to learn these skills in several forms such as recount, descriptive, narrative, procedure, report, exposition, biography, as well as news item texts to enable the students in exploring their ideas. Indonesian secondary school students have problems with English writing due to the traditional method of teaching the subject and as a result, tend to practice without knowing how to write appropriately. Teachers provide, correct, and grade from limited topics which the students are to select from. Since accuracy is the main focus of a writing lesson, teachers 
focus solely on the product or output and overlook the process which is the most vital part (Lestari, 2006). Also, product-based approaches are predominantly concerned with language structure and writing progress which are mostly input imitations, in the form of texts postulated by the teacher(Badger \& White, 2000). This unfavorable situation has been in occurrence since these students were in elementary school, and as a result, they feel bored, demotivated, and considers writing a burdensome activity. Moreover, Indonesian students are rarely explicitly directed on how to use writing strategies which can support them to become good writers and are offered little or no direction by the teachers. Therefore, there is a need for English teachers to understand their students' writing strategies because the tutors may be unaware of the importance of teaching them.

The primary goals of this study are to recognize the students' strategies when writing recount texts and investigate the influence of writing strategies used on their writing quality. Meanwhile, the students were from one of the Buddhist High Schools in West-Jakarta and had gained high exposure to English because some subjects were conducted in the language. Although they had no problems with communicating in English, they still had difficulties with developing their writing.

\section{Writing Process and Writing strategies}

Writing is a long process as writers have to experience several stages to generate a final product (Flower \& Hayes, 1981; Graves, 1982; Harmer, 2007). Although writing is a long, intricate, and complicated process, it is dynamic as the writer undergoes not one but several steps which include planning, writing, drafting, as well as reviewing. Therefore, the process is a sequence of stages leading to problem-solving and this cycle continues when the writer unintentionally or intentionally begins a topic and ends when the project is published (Graves, 1982). In each stage, the writers utilize some of these strategies which are consciously and individually implemented by them to resolve problems or accomplish objectives throughout the writing process (Shapira \& Hertz-Lazarowitz, 2005; Torrance, Thomas, \& Robinson, 1994). For instance, as soon as the topic of a task is acquired, they read continuously to analyze and understand the demands of the task (Rp) and pause $(\mathrm{P})$ to evaluate how to connect the new and old sentences to promote coherence. Some studies have revealed that the regular use of appropriate writing strategies can control students' writing problems and teach them how to write successfully and independently (Shafiee, Koosha, \& Afghari, 2013).

\section{Writing Strategy Taxonomy}

The Think-Aloud technique is commonly used by researchers to observe various writing strategies(Abdel Latif, 2019; Bai, 2018; Perl, 1979). According to (Patton, 1988) this method aims to make the implicit procedures and mental activities of a specific task explicit. Writers verbalize all their thoughts while using this technique and then document, transcribe and study them. Finally, the collected data are called 'verbal reports or protocols' from which researchers classify the strategies applied by the writers while performing specific tasks by using coding schemes, systems, or taxonomies.

According to Hsiao \& Oxford (2002), strategies are described based on specific categories or groups as perceived by different scholars, which makes it demanding to classify all the ESL/EFL writing strategies acknowledged by researchers. However, Perl (1979) was the first researcher that used coding schemes to describe the composing processes of L1 subjects'. Since then, numerous studies on L1 or L2/ EFL using the Think-Aloud method have depended on specific coding schemes to describe writing processes. Also, Perl (1979) stated three major 


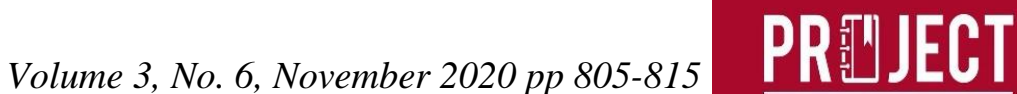

coding schemes which are talking, reading, and writing, and these operations are of different kinds, thus, creating the need to differentiate among the various types. These operations were distinguished into 16 significant categories during the $\mathrm{L} 1$ research and the coding schemes were individually classified to list writing behaviors without grouping them into major categories. Many researchers in the L2/FL writing field developed personal modified versions of Perl's coding scheme either by adding few units and/or narrowing it down, and they included Arndt (1987), and (Alhaisoni, 2012).

\section{English Writing Research at Secondary Schools}

Several studies have been conducted by some researchers on writing strategies used by EFL and ESL High School Students (Alkubaidi, 2018; Cer, 2019; Liu, 2015; Maarof \& Murat, 2013; Mastan, Maarof, \& Embi, 2017; Mistar \& Parlindungan, 2014). The study by (Mastan et al., 2017) involved sixty-three (63) intermediate-level students from two classes. Consequently, this research was aimed at examining the strategies applied by secondary school students while writing their expository texts. One class was randomly given as the instruction group and exposed to the Self-Regulated Strategy Development (SRSD) approach which concentrated on metacognitive and cognitive writing strategies, while the other was the control group. Meanwhile, the results showed that the strategy instruction group did better than the control group. Another study conducted by Eliwarti \& Maarof (2014) used a questionnaire to discover the strategies used while writing and the participants were secondary students with different levels of English knowledge. Subsequently, the findings demonstrated that students used moderate writing strategies and showed relatively similar frequencies of use with the major difference being the type of strategies employed. Furthermore, a study by Peñuelas (2012) investigated the self-reported strategies used by two hundred and thirty-one students (231) when writing their tasks by employing a questionnaire. The outcomes showed that although the proficient and less proficient students applied a variety of strategies, the proficient ones used cognitive, metacognitive, and compensation strategies followed by social, affective, and memory strategies. Therefore, users of more and varied strategies got better grades.

Most of the previously conducted research on writing strategies used by High School students did not use Think Aloud procedures. Instead, Self-reported strategies Eliwarti \& Maarof (2014), Self-Regulated Strategy Development(Mastan et al., 2017), as well as questionnaires were used Liu (2015). However, in this study, the data were obtained mainly from ThinkAloud Protocols (TAPs), and conducting the procedures was not easy, especially when the participants were still young, e.g. secondary school students. Meanwhile, verbalizing students' thoughts will influence and change a writing task during the completion and also increase the writers' cognitive processing load. This will stimulate a form of dual-task condition and as a result, it is not a pure measure of their thoughts. To overcome this problem, the researcher carefully trained the students and only those that met the criteria joined in, which was why only three students participated in this research. Think-aloud Protocols/reports (TAPs) are possibly an excellent way to offer some understanding on different issues, while data production can report the students' cognitive processes and use of writing strategies (Bowles, 2010).

\section{METHOD}

\section{Participants}

This research was conducted in a private Buddhist Senior High school in West Jakarta and the participants were tenth-grade students in the second semester of the 2019/2020 academic 
calendar. There were two classes for these students, each comprising twenty members, and both were taught by the same English teacher. Also, the school emphasized the importance of this language and Mandarin by conducting English classes and extracurricular twice and once weekly respectively. Meanwhile, the researcher worked collaboratively with the English teacher while conducting the study and selected the 10th-grade students because they needed to be trained on how to use writing strategies from scratch. All the students had attained sufficient exposure to English as they were in Junior High school and often communicated with their friends and teachers via the language. However, only a few were able to produce well-organized and meaningful written pieces and they were selected to join the research based on their daily and mid-term test performances. Those were good at writing and other skills such as listening, speaking, and reading and students that were good at these skills asides from writing were chosen. Although seven students met the criteria, only three were eligible to join the research while the other four gave up on participating in the Think-Aloud procedures. The unselected students were unable to verbalize and write at the same time, which was also why the participants were limited.

\section{Instruments}

The focal instruments applied in this study were Think-Aloud Protocols (TAPs), observations, semi-structured, and retrospective interviews. The data collected from verbalizations and the texts produced by the writers were called Think-Aloud Protocols (TAPs) which were employed to identify the strategies used after evaluation with a coding scheme. A retrospective interview was used directly to triangulate the protocols after the writers had completed the Think Aloud procedures, and this was conducted on the same day right after the writing session was over to increase data consistency.

\section{Procedures}

Before the actual research, the students were trained on how to partake in the Think-Aloud procedures bi-weekly for two weeks. In the actual research, they were asked to write a recount text type in English using the think-aloud technique and the allotted time was seventy-five minutes. The topic was "My Last Holiday" which was to be written within the stipulated time frame, while the recount text type was chosen because it is usually allocated to tenth-grade students according to Curriculum 13. Furthermore, the retrospective interview was conducted immediately after the writing was completed, while a modified version of Perl's (1979)was used to clarify the strategies used throughout the process. A week after the data was analyzed; a semi-structured interview was conducted to identify the responses, motives, feelings, and attitudes towards their writing.

\section{Data Analysis}

In the think-aloud analysis, the videotapes were coded using a modified version of the Perl's (1979) model. Consequently, there are twelve strategies used by student writers in L2, and these were analyzed by transcribing the audiotapes and video recordings for each subject. Then, the data were segmented and coded.

The observations occurred simultaneously as the students were writing aloud. While the writer wrote and verbalized an essay, the researcher sat behind and observed what the student did, how they behaved, what was done when difficulty was experienced, as well as what strategies were used to overcome their writing problems. The students' activities were filmed and recorded, and other actions such as the reason for pausing, reading, or rereading the text were jotted down. Consequently, this information was used in the retrospective interview. 
Furthermore, a semi-structured interview was directed for the three students for duration of 20 minutes each to explore their previous experiences with writing in English. The interviews were also intended to discover the subjects' ideas and attitudes towards using TAPs while writing in English.

\begin{tabular}{|c|c|}
\hline WRITING STRATEGIES & DEFINITION \\
\hline Reading The Prompt (Rp) & Analyzing the demands of the writing topic \\
\hline Global Planning (Gp) & Writing detailed planning of general organization \\
\hline Rehearsing (Rh) & $\begin{array}{l}\text { Attempting to generate or retrieve information on the } \\
\text { topic and developing these ideas }\end{array}$ \\
\hline $\begin{array}{l}\text { Reading/Rereading the previous } \\
\text { sentence }(\mathrm{s}) / \text { paragraph }(\mathrm{s})(\mathrm{Re})\end{array}$ & $\begin{array}{l}\text { - Trying to develop the content of their } \\
\text { writing } \\
\text { - } \quad \text { Deciding how to connect the text with } \\
\text { what writers are going to write next } \\
\text { - } \quad \text { Keeping the coherence and the flow } \\
\text { between the present sentence and the } \\
\text { following sentence } \\
\text { - } \quad \text { Running out of ideas }\end{array}$ \\
\hline Organizing The Paragraph (Op) & Organizing what to write in writing/ drafting stage \\
\hline Using Dictionary (Ud) & $\begin{array}{l}\text { Looking up or confirming lexicon, grammatical, } \\
\text { semantic or spelling doubts or alternatives words } \\
\text { (synonyms, or antonyms). }\end{array}$ \\
\hline \multicolumn{2}{|l|}{ Using L1 (Ul) } \\
\hline Local Planning (Lp) & what to write next \\
\hline Pausing (P) & $\begin{array}{ll}\text { - } & \text { Reformulating the idea } \\
\text { - } & \text { Taking a rest a while after writing long } \\
& \text { sentences } \\
\text { - } \quad \text { Expressing the complexity of the idea }\end{array}$ \\
\hline Reviewing (Re) & Reading/ rereading the text after completing writing \\
\hline Editing (Ed) & Making changes in the text; not changing the meaning \\
\hline Revising (Rv) & Any changes affecting the meaning of the text \\
\hline
\end{tabular}

Table 1: Coding Taxonomy adapted from Perl's (1979) model

\section{RESULTS AND DISCUSSION}

\section{Results}

\section{Writing Strategies Applied By the Students}

The data from the protocols revealed the strategies applied by the students, along with the frequency from the beginning up until when the writings had been accomplished were calculated by the researcher and writing lecturer and shown in Table 2. 


\begin{tabular}{l|c|c|c}
\hline Reading The Prompt (Rp) & V & VV & VVV \\
Global Planning (Gp) & - & $\mathbf{V}$ & $\mathbf{V}$ \\
Rehearsing (Rh) & VVV & VV & VV \\
Reading/Rereading the previous & VVV & VVV & VVVVVVVVV \\
sentence(s)/ paragraph (s) (Re) & & & \\
Organizing The Paragraph (Op) & - & V & V \\
Using Dictionary (Ud) & VVVV & VVVV & V \\
Using L1 (Ul) & VV & VV & VV \\
Local Planning (Lp) & VVVV & VVV & V \\
Pausing (P) & VVV & VVV & VVVV \\
Reviewing & V & VV & VVV \\
Editing (Ed) & VVVV & VVVVV & VVVVVV \\
Revising (Rv) & V & - & VVVVV \\
\hline
\end{tabular}

Table 2: Writing strategies used by students when writing in L2 (English)

As soon the students got the topic, candidate $\mathrm{C}$ reread it about three times and paused to think of the demands, and then made copious notes which were thoroughly organized into three parts, namely the introduction, content, and conclusion. Following this, the student paused and reread the phrases and sentences to get more ideas for the actual text and the writing was planned globally and thoroughly as the student read the plans before writing the text. Therefore, student $\mathrm{C}$ relied on rereading and pausing to develop ideas in the planning stage. Conversely, student B reread the prompt twice, rehearsed several times to get the idea which was written in the form of scribbles, and after planning, commenced writing immediately. Therefore, student B relied on rehearsing to develop the plans. Meanwhile, student A read the prompt once and began to write the essay immediately after as the candidate had planned mentally without drafting out the ideas.

Student C's writing was a highly recursive process as the candidate paused to reread the previous sentences or paragraphs, look up difficult words in the dictionary, use the L1 occasionally, rehearse, revise, and edit the text before progressing. The other two writers' processes appeared to be less recursive than student $\mathrm{C}$. Also, there was less back and forth movement within the text which was not shown to either create chances or impose constraints. Both students used their dictionaries frequently for spelling checks and discovering new words. All the candidates were capable of thinking in the L2 and only performed minor translations from the LI to the L2 when they encountered problems while searching for equivalents.

The types of activities in the final stage varied significantly between writers. Student $\mathrm{C}$ only reviewed the text by reading and rereading it several times and made no changes as the text had already been extensively revised and edited during the writing/ drafting stage. Therefore, the student appeared to be confirming that no information had been omitted. Alternatively, student B made several editing changes while reading the text, but made no revisions in this stage, while student A acted similarly to student B but made a final edit and glanced through the text once. 


\section{Students' Writing Strategies and Writing Quality}

It was apparent in this research that effective strategies were closely related to students' writing quality. The rubric system from Boardman \& Frydenberg (2008) was used to rate students' writing and student $\mathrm{C}$ achieved the highest score at 85, while B and A got 68 and 62 respectively. There were two raters: the researchers and a lecturer who is the researcher's colleague, and also teaches Academic Writing.

\begin{tabular}{cc}
\hline Score Range & Category \\
\hline $100-90$ & Excellent \\
$89-80$ & Very Good \\
$79-70$ & Good \\
$69-60$ & Fair \\
$59-0$ & Poor
\end{tabular}

Table 3

The Interpretation of the Score from Boardman \& Frydenberg (2008)

\begin{tabular}{cc}
\hline STUDENT & SCORE \\
\hline A & 62 \\
\hline B & 68 \\
\hline C & 85 \\
\hline
\end{tabular}

Table 4: Students' score when writing “ My Last Holiday”

\section{Discussion}

From the explanation above, all the students used similar writing strategies, however, the occurrences of reading and rereading the previous sentences and paragraphs were different. Student $\mathrm{C}$ applied this writing strategy at a high frequency and paused to reread the previous sentences and paragraphs for several reasons which were to edit, revise, generate, and develop ideas. The most crucial concerns are how to choose, monitor, direct, and apply suitable strategies efficiently and at the right times(Macaro, 2006; Pennington \& So, 1993). The other two writers, A and B, appeared to be unaware of the recursiveness of writing and were inclined to apply a linear process, possibly because they did not practice writing frequently. In the planning stage, all the students used different techniques. According to some researchers, a successful writer needs some time to plan their research essays (Mahmoud Tabari, 2019; Victori, 1999). Student C systematically planned what to write in the first, second, and third paragraphs, and wrote them out thoughtfully and carefully. This candidate rarely planned while writing and always went back to the initial plans which were used as a guide while writing. However, the other two often planned what to write locally, especially student $\mathrm{A}$, an action that led to superficial content and a lousy text. This finding is in line with the results of the researches by van Weijen et al., (2009) and Arifin (2020). 
Moreover, Student $\mathrm{C}$ stuck to and followed the initial plans and also knew which writing strategies were most suitable and how to appropriately select, control, direct, and use them effectively. The other two candidates were unable to control and direct the process which was often demonstrated in their writing as they did not plan properly. Therefore, they changed plans often and locally when new ideas and difficulties were encountered and were also unaware that reviewing their writing could improve the quality. These students focused solely on editing their grammar, spelling, and vocabulary. Thus, applying writing strategies suitably and efficiently distinguishes between skilled and less-skilled writers(Chien, 2012).

\section{CONCLUSION}

The current study explores Indonesian High School students' L2 (English) writing strategies and how the startegies relate to their writing quality. Some fundamental findings were demonstrated in this research. The use of strategies is crucial in writing, and students' effective use of the strategies can generate meaningful writings. Some researchers (Abdullah et al., 2011; Khongput, 2020) state that writing strategies play an essential part in differentiating between skilled and less-skilled writers. Therefore, these strategies should be introduced and taught explicitly in the writing classes when students already have a sufficient understanding of grammar. Students also need to be taught how to concentrate on overall content matters rather than trivial mechanical issues. These may not take much time but are less effective and generate poorer outcomes. Moreover, teachers have to emphasize planning and reviewing texts and teaching students these methods thoroughly. Writing is recursive, and it is essential to read the entire text to inspect the coherence and accuracy. Finally, a workshop could be useful in language classes to increase students' and teachers' awareness of the writing strategies learners tend to adopt.

\section{ACKNOWLEDGMENTS}

I would like to express my gratitude to Lembaga Penelitian Uhamka - the Muhammadiyah University Research Institute chaired by Prof. Dr. Suswandari which has provided the opportunity to conduct my internal research and also has supported the researcher by giving grants so that this research can be carried out.

\section{REFERENCES}

Abdel Latif, M. M. M. (2019). Using think-aloud protocols and interviews in investigating writers' composing processes: combining concurrent and retrospective data. International Journal of Research and Method in Education, 42(2), 111-123. https://doi.org/10.1080/1743727X.2018.1439003

Abdullah, M. R. T. L., Abu Bakar, Z., Ali, R. M., Raja Yaacob, R. A. I., Abdur-Rahman, M. a., Embong, A. M., \& Bin Amar, A. Z. (2011). Writing strategies of Malaysian ESL undergraduate engineering learners. International Journal of Engineering \& Technology IJET-IJENS, 11(April), 1-9.

Alhaisoni, E. (2012). A think-aloud protocols investigation of Saudi English major students' writing revision strategies in L1 (Arabic) and L2 (English). English Language Teaching, 5(9), 144-154. https://doi.org/10.5539/elt.v5n9p144

Alkubaidi, M. (2018). A Comparative Analysis of Writing Strategies and Performance in a Saudi University. Studies in Self-Access Learning Journal, 9, 425-443. https://doi.org/10.37237/090403 


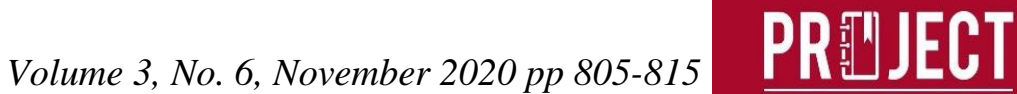

Arifin, S. (2020). Investigating the L2 Writing Strategies Used by Skillful English Students. Jurnal Pendidikan Dan Pengajaran, 53(1), 78. https://doi.org/10.23887/jpp.v53i1.24939

Arndt, V. (1987). Six writers in search of texts: A protocol-based study of 11 and 12 writing. ELT Journal, 41(4), 257-267. https://doi.org/10.1093/elt/41.4.257

Badger, R., \& White, G. (2000). A process genre approach to teaching writing. ELT Journal, 54(2), 153-160. https://doi.org/10.1093/elt/54.2.153

Bai, B. (2018). Understanding primary school students' use of self-regulated writing strategies through think-aloud protocols. System, 78, 15-26. https://doi.org/10.1016/j.system.2018.07.003

Boardman, C. A., \& Frydenberg, j. (2008). Writing to Communicate (3rd Editio, Vol. 17). https://doi.org/10.1097/00005721-199203000-00001

Bowles, M. A. (2010). The think-aloud controversy in second language research. In The ThinkAloud Controversy in Second Language Research. https://doi.org/10.4324/9780203856338

Cer, E. (2019). The Instruction of Writing Strategies: The Effect of the Metacognitive Strategy on the Writing Skills of Pupils in Secondary Education. SAGE Open, 9(2). https://doi.org/10.1177/2158244019842681

Chien, S. C. (2012). Students use of writing strategies and their English writing achievements in Taiwan. Asia Pacific Journal of Education, 32(1), 93-112. https://doi.org/10.1080/02188791.2012.655240

Eliwarti, \& Maarof, N. (2014). The Effects of types of writing approaches on EFL students' writing performance. Selt, 11-12(June), 112-119. Retrieved from file:///C:/Users/user/Downloads/6692-13320-1-SM (3).pdf

Farooq, M. S., \& Uzair-ul-hassan, M. (2012). Opinion of Second Language Learners about Writing Difficulties in English Language Opinion of Second Language Learners about Writing Difficulties in English Language Today, communication across the cultures and nations is more important than ever. A Research Journal of South Asian Studies, 27(February), 182-194. Retrieved from https://www.researchgate.net/publication/330170345_Opinion_of_Second_Language_Le arners_about_Writing_Difficulties_in_English_Language

Flower, L., \& Hayes, J. R. (1981). A Cognitive Process Theory of Writing. College Composition and Communication, 32(4), 365. https://doi.org/10.2307/356600

Graves, D. H. (1982). A Case Study Observing the Development of Primary Children's Composing, Spelling, and Motor Behaviors during the Writing Process. Retrieved from https://files.eric.ed.gov/fulltext/ED218653.pdf

Harmer, J. (2007). How to teach English (New Editio). Retrieved from https://www.academia.edu/34720971/How_to_Teach_English_2nd_Edition_Jeremy_Har mer.PDF

Hsiao, T. Y., \& Oxford, R. L. (2002). Comparing theories of language learning strategies : A confirmatory factor analysis. Modern Language Journal, 86(iii), 368-383.

Khongput, S. (2020). Metastrategies Used by EFL Students in Learning English Writing: LEARN Journal : Language Education and Acquisition Research Network Journal, 13(2), 93-104. Retrieved from https://files.eric.ed.gov/fulltext/EJ1258799.pdf

Lestari, L. A. (2006). The Interactional Approach to The Teaching Of Writing and Its Implications for Second Language Acquisition. TEFLIN Journal, 17(1), 42-56. https://doi.org/10.15639/teflinjournal.v19i1/42-56

Liu, G. (2015). Investigating the English Writing Strategies Used by Chinese Senior High School Students. Theory and Practice in Language Studies, 5(4), 844. https://doi.org/10.17507/tpls.0504.21

Maarof, N., \& Murat, M. (2013). Writing strategies used by ESL upper secondary school 
International Education $\quad$ Studies, 6(4), 47-55. https://doi.org/10.5539/ies.v6n4p47

Macaro, E. (2006). Strategies for language learning and for language use: Revising the .... Modern Language Journal, 90(3), 320-337. Retrieved from http://www.jstor.org/stable/3876831\%5Cnpapers2://publication/uuid/FBB365BD-CF39485A-A475-8708D966E40B

Mahmoud Tabari. (2019). Differential Effects of Strategic Planning and Task Structure on L2 Writing Outcomes. Reading \& Writing Quarterly, O(0), 1-19. https://doi.org/10.1080/10573569.2019.1637310

Mastan, M. E. B., Maarof, N., \& Embi, M. A. (2017). The effect of writing strategy instruction on ESL intermediate proficiency learners' writing performance. Journal of Educational Research and Review, 5(5), 71-78.

Mbau, A. T., \& Marhum, M. (2014). an Analysis on the Subject-Verb Agreement Errors in Writing Paragraph Made By the Second Semester Students. E-Journal of English Language Teaching Society (ELTS), 2(2), 1-15. Retrieved from file:///C:/Users/user/Downloads/3036-9337-1-PB.pdf

Mistar, J., \& Parlindungan, F. (2014). Strategies of learning English writing skill by Indonesian senior hgh school students. Arab World English Journal, 5(1), 290-303.

Nunan, D. (1999). Second Language Teaching \& Learning. Retrieved October 30, 2020, from https://www.bookdepository.com/Second-Language-Teaching-Learning-DavidNunan/9780838408384

Pablo, J. C., \& Lasaten, R. C. (2018). Writing Difficulties and Quality of Academic Essays of Senior High School Students. Asia Pacific Journal of Multidisciplinary Research, 6(4), 46-57. Retrieved from http://www.apjmr.com/wp-content/uploads/2018/08/APJMR2018-6.4.06.pdf

Patton, M. Q. (1988). Qualitative Evaluation Methods. Retrieved from https://www.gwern.net/docs/sociology/1980-patton-qualitativeevaluationmethods.pdf

Pennington, M. C., \& So, S. (1993). Comparing writing process and product across two languages: A study of 6 Singaporean university student writers. Journal of Second Language Writing, 2(1), 41-63. https://doi.org/10.1016/1060-3743(93)90005-N

Peñuelas, A. B. C. (2012). The writing strategies of american university students: Focusing on memory, compensation, social and affective strategies. Elia, 12(1), 77-113. Retrieved from http://institucional.us.es/revistas/elia/12/art_4.pdf

Perl, S. (1979). The Composing Processes of Unskilled College Writers. Source: Research in the Teaching of English, 13(4), 317-336. Retrieved from http://www.jstor.org/stable/40170774\%5Cnhttp://www.jstor.org/stable/40170774

Shafiee, S., Koosha, M., \& Afghari, A. (2013). The effect of conventional , web-based , and hybrid teaching of pre-writing strategies on Iranian EFL learners ' writing performance. International Research Journal of Applied and Basic Sciences, 4(2), 393-401.

Shapira, A., \& Hertz-Lazarowitz, R. (2005). Opening windows on arab and jewish children's strategies as writers. Language, Culture and Curriculum, 18(1), 72-90. https://doi.org/10.1080/07908310508668734

Torrance, M., Thomas, G. V., \& Robinson, E. J. (1994). The writing strategies of graduate research students in the social sciences. Higher Education, 27(3), 379-392. https://doi.org/10.1007/BF03179901

van Weijen, D., van den Bergh, H., Rijlaarsdam, G., \& Sanders, T. (2009). L1 use during L2 writing: An empirical study of a complex phenomenon. Journal of Second Language Writing, 18(4), 235-250. https://doi.org/10.1016/j.jslw.2009.06.003

Victori, M. (1999). An analysis of writing knowledge in EFL composing: A case study of two effective and two less effective writers. System, 27(4), 537-555. 


\section{Volume 3, No. 6, November 2020 pp 805-815}

https://doi.org/10.1016/S0346-251X(99)00049-4 